anterior portions of the thigh, of the penis and scroium, but there was no motor paralysis of the lower limbs. Ollivier, writing about the case in 1837, evidently considered it as a curiosity, as he could not understand the absence of paralysis in the presence of spinal cord symptoms, as bladder disturbances, but adds that such a strange combination evidently occurred only when the lumbar region is involved. In 1849 Jutins described a bullet lesion of the cauda equina of fourteen years' duration. The bullet was not removed, int the paralysis slowly disappeared in the left leg, and remained in the right. The postmortem showed the bullet implanted in the vertebral canal, where it cut the right half of the spinal cord, or rather that of the cauda equina, leaving the left half intact.

I feyden" mentions two cases of bullet lesions of the cauda equina reported by Socin and Klebs. In one, the lesion was to the right of the fourth lumbar vertebra, in the other above the right posterosuperior spine. The symptoms gradually disappeared, though the bullets were not removed. In Lamb's case ${ }^{7}$ the patient carried the bullet in the cauda equina for eighteen and one half years, and it was found at the necropsy at the level of the fifth lumbar vertebra, where it descended from above (the fourth lumbar) following suppura-. tion.

The patient suffered from partial paralysis of the left leg, which set in nine years after the shooting, from continuous pain in the back and the left leg, urinary disorders and atrophy of the right leg. In 1904 Weisenburgs reported a case of cauda equina lesion by a bullet which perforated the fifth lumbar vertelura (loss of sphincter control the first two weeks, loss of Achilles jerk, increased bilateral knee jerk), but the bullet was not located. In the same year Fnglemann" reported a case in which the bullet entered the median line between the fifth lumbar and the first sacral vertebrae. The patient was operated on five days later, and sixteen days after the operation the pain totally disappeared, though the sensory disturbances were still present four months later around the arms.

Finally the cases of Raymond and Rose, and of Raymond must be mentioned. In the former ${ }^{10}$ the bullet, as in our case, was located at the level of the third lumbar vertebra, and gave practically identical symptoms: lessened motor power in the lower limbs, atrophy of the right thigh and antero-external muscles of the leg, loss of the right patellar and Achilles jerks, which were followed six weeks later by loss of sphincter control, and anesthesia of the perineum, scrotum, penis and posteromedian surface of the thigh. The latter symptoms were due to the sinking of the bullet to the first sacral vertebra. At the operation, which was done about three months after the injury, the bullet was found to be movable and removed, followed by improvement in the patient's condition. Another patient of Raymond ${ }^{11}$ had the bul-

5. Hutin: Jour. de méd, et de chir. prat., $1849, \mathrm{xx}, 512$.

6. Leyden, E.: Traité clinique des maladies de la moelle épinière, Translated by E. Richard \& C. Viry, Paris, 1879, p. 262.

7. Iamb, quoted from Vincent, E.: Des plaies par coup de feur de la moelle épinière, Rev. de chir., 1892, p. 89.

8. Weisenburg, T. H.: A Clinical Report of Three Cases of Injury of the Lower Spinal Cord and Cauda Equina, Am. Jour. Med. Se.. May, 1904, Case 2.

9. Englemann, Fritz: Akute Kompression der Cauda Equina durch ein Projektil. Operation; Heilung, München. med. Wchnschr., 1904, No. 51 , p. 2292.

10. Raymond and Rose: Compression des racines de la queue de cheval par balle de revolver, laminectomie, guérison, Rev. neurol., cheval par

11. Raymond, F.: Sur quelques affections de la queue de cheval, Arcli. gén. de méd., 1906, p. 1940. let also at the level of the third lumbar vertebra, and was operated on about three months after the injury. Here also the bullet was movable and removed, with some improvement in the patient's condition.

These are practically all the cases that can be found in the literature in reference to the bullet lesions of the cauda equina. Of all the cases only those of Raymond bear some resemblance to ours, yet there is a difference in the length of time the lesion lasted: in our case, six years; in Raymond's, only three months. The results, however, were equally good in our case, though the operation was much more difficult and complicated.

3059 Jackson Boulevard.

\section{PUBLIC HEALTH MEASURES IN RELATION TO VENEREAL DISEASES *}

WILLIAM F. SNOW, A.M., M.D.

General Secretary, American Social Hygiene Association NEW YORK

"Social hygiene" is an inclusive phrase covering activities of which the campaigns against venereal diseases and prostitution are only a part, but necessarily in past years the most prominent part. Eventually the social hygiene movement will become recognized by the public as a constructive effort to promote all those conditions of living, environment and personal conduct which best protect the family as an institution and secure a rational sex life for the individuals of each generation.

Prior to 1900 , certain scientific and sociologic data were recorded in their bearing on the reduction of syphilis and gonorrhea, but no effective public health measures were instituted. From 1900 to 1912, existing facts were marshaled for educational campaigns, and new facts of the highest importance were discovered. In the medical field there were added new observations of gonorrhea, its ravages, communicability and treatment, the discovery of the organism of syphilis in 1905 , the development of the Wassermann reaction in 1907 , the preparation of salvarsan for the treatment of syphilis in 1910, and in 1911 the successful experimental inoculation of syphilis and artificial cultivation of its organism. These advances made possible by 1912 a practical campaign against venereal diseases as soon as public opinion should be developed in support of it. In the law-enforcement field, the records of the past twenty years show many persistent and self-sacrificing efforts to utilize existing statutes and to devise new legislative and administrative measures for the repression of commercialized practices inimical to high standards of public morality and health. In the religious and ethical fields, likewise, notable efforts have been made to bring about necognition of the importance of good environment and personal observance of moral living as forces in any campaign for the ultimate eradication of venereal diseases and prostitution as great social ills. The organization and extension of social hygiene society campaigns, and the promotion of similar work by numerous other national

\footnotetext{
* Presented at the Pan-American Scientific Congress, Washington, D. C., Dec. 30,1915 .

* Because of lack of space this article is abbreviated in THE Journal. The complete article appears in the author's reprints. A copy of the latter will be sent by the author on receipt of a stamped, addressed envelope.
} 
and state associations, have now prepared the way for a serious attempt to deal effectively with this great medical-social problem.

Syphilis and gonococcus infections are foremost among a group which may be designated social as well as individual disorders affecting people's lives in many tragic ways, and therefore to be attacked through social treatment as well as medical treatment. It will be profitable to summarize at this point certain facts. Venereal diseases are communicable infections due to identified organisms; their methods of transmission are known, and a practical laboratory and clinical technic has been worked out for diagnosing each of them; they are widely prevalent throughout the world and are not limited to any race, sex, age or condition of people; they find their chief opportunity for dissemination in the sex relations of infected individuals with other individuals who are susceptible; they are largely but not exclusively transmitted through the promiscuous sex relations defined as prostitution and condemned by society as harmful alike to the health, the morals and the social progress of a people; recent methods of therapy make practicable the shortening of the period of infectivity and improve the chances of ultimate recovery of the patient submitting to early and thorough treatment; once contracted, they may run their course to practical recovery with or without medical assistance, but under present conditions an unknown and large percentage of those infected never conpletely regain their health or cease to be carriers, and, therefore, are a continuous menace to society. Syphilis in its early stages is especially a public danger, while in its late manifestations the menace is largely confined to the individual himself ; gonorrhea, on the contrary, while a public danger at all times, is particularly damaging to the individual in its early acute development, and later becomes an insidious danger to those intimately associated with him.

With these general facts before us, the medical lines of attack are clear: 1. We must seek by cooperation with or control of the infected individual to prevent his infecting others. 2. We must endeavor by education and administrative measures to enable uninfected individuals to protect themselves against infection. 3. We must develop, so far as may become possible, the defenses of society calculated to prevent the recrudescence of venereal diseases in any community which is measurably reducing them.

The measures which have been advocated to meet this program may be grouped as follows: (1) management of existing cases; (2) prophylactic measures; (3) measures contributing to their reduction and ultimate eradication.

\section{MANAGEMENT OF EXISTING CASES}

1. Provision of public health laboratory equipment for free examinations for evidence of syphilis and gonococcus infections.-So many state and municipal health laboratories in the United States have now established this work that its practicability has been demonstrated and its continuance assured. In 1914, the New York City Health Department examined 59,614 specimens, 75 per cent. of which were received from private physicians. The Massachusetts State Department of Health receives more than 1,000 specimens per month for its Wassermann laboratory, and has extended this service to patients of private physicians.
2. Provision of ample facilities at public expense for cinical diagnosis and advice in cases of possible syphi. lis and gonorrhea.

Interesting and encouraging experiments in this direction have been recently made. By the close of the current year, the New York City Department of Health will have aided, through its advisory clinic, more than 3,000 new patients. ${ }^{1}$ The Oregon State Board of Health operates a similar department for diagnosis and personal advice, and in addition has developed an extensive correspondence with persons in all parts of the state who write for information. More than 5,000 interviews and letters have been handled in the past four years, the majority of individuals having applied after seeing one of the health board venereal-disease placards. With minor modifications of the general plan, a sufficient number of other health departments are now beginning this work to insure its success in the United States.

3. Provision of adequate treatment of ambulatory cases free of cost to those requiring public assistance.

Having provided laboratory and clinical facilities and medical advisers, it is essential to any effective administrative campaign that persons infected with syphilis or gonorrhea shall be given proper treatment and supervision until they are returned to health and are no longer a source of danger to others. These may be divided for practical purposes into ambulatory (those who may come to the physician's office or the dispensary for treatment) and hospital cases. Medical opinion has not been fully formulated as yet on what should constitute admission into these respective groups, but the prevalence of the diseases makes it mandatory that the ambulatory group shall be as large as possible.

Of the ambulatory patients, those who can pay for the services of private physicians are relatively of less danger to the community health than those who must depend on public assistanice; but medical records show how very frequently the physician fails to study his venereal cases, and entirely neglects his responsibility for the protection of society and the patient's family. The highest efficiency of the private general practitioner in the treatment of venereal infections must be sought, because, with this more than with any other group of communicable diseases, the practitioner can be utilized as the representative of the health department during the indefinite periods of necessary surveillance.

Without attempting to estimate the percentage of venereal patients who can pay for their treatment and those who cannot, it is known that the proportion of the latter is high. It is also known that a certain percentage constitutes a middle group comprising those who can pay something; the evening pay clinic experiments have demonstrated this fact. Administrative efficiency demands just as good treatment for the indigent case as for the private pay case; administrative economy demands arrangement for such partial payment as may be practicable. In all cases, the interests

1. This number included men and women, 316 of whom came during the first six months in response to a small paid advertisement of free confidential advice carried by the health department in some of the daily newspapers publishing quack notices. These applicants for diagnosis and advice are told the nature of venereal diseases, the danger of improper treatment, and the necessity for strict adherence to their physicians' orders. The danger of discontinuing treatment and the unreliability of the so-called sex disease "specialists" are stated. The importance of continence for the sake of the individual and of society is emphasized. If applicants who require treatment cannot afford the services of a private physician, they are referred to a list of accredited clinics - public and private-for proper attention. 
of good citizenship demand conditions under which the scif-respect and privacy of the patient may be retained.

There is now being worked out in the United States a number of valuable experiments in free and pay clinics for venereal diseases, and evidence is being collected which demonstrates the need for the enforcement of standards for equipment, service and requirements for discharge of venereal patients from genito-urinary and gynecologic clinics. A recent survey $^{2}$ to determine how many clinics in New York were meeting the requirements of the Associated Outpatient Clinics reported only seven approved clinics for syphilis out of twenty-seven, and but four approved out of twenty-six clinics for other venereal diseases. Many of these could, with small effort, meet the requirements, but twelve were found hopelessly bad. Furthermore, in only two of the clinics was detailed analysis of a year's records possible without a prohibitive amount of work. The records of these two clinics showed ${ }^{3}$ for gonorrhea only 9.7 and 9.4 per cent., respectively, dismissed as cured. These figures are probably fairly typical of every part of the United States. Dr. Davis of the Boston Dispensary reported 11.4 per cent. of 450 gonorrheal patients as cured; Dr. Sanford of the Lakeside Hospital Dispensary, Cleveland, reported a series in which 12 per cent. were cured. Equally unsatisfactory results have been found in studies of syphilis.

What this means to the public can perhaps be paralleled by the spectacular outbreak of smallpox which occurred in Montreal in 1887 when the panic-stricken inmates of a hospital, after exposure to an unrecognized casc, were permitted by the authorities to scatter through the city with the result that several thousand pcrsons developed the disease and many died. . Outbreaks of venereat diseases are not spectacular or sudden, nor do the causal organisms find ready opportunity to attack new victims except through the intimate relations of sexual intercourse; but their insidious spread, aided by the prolonged periods of years during which infected individuals may be carriers, makes them far more dangerous than smallpox. In the development of adequate medical and social treatment of ambulatory venereal patients, we have presented to health departments a concrete problem for which solution is demanded by every interest, economic, social and moral.

4.- Provision of adequate hospital facilities, free of cost to individuals when necessary, for syphilis and gonorrhea cases in all stages in ahich hospital care is an advantage to the patient or a protection to the public.

In a general way, what has been stated concerning private treatment, pay clinic, and free clinic service for ambulatory cases applies to similar classes of hospital cases. The hospital adds chiefly a bed and the more complete supervision possible through discipline and organized professional and nursing staffs. But these additions in certain manifestations of syphilis and gonococcus infection make all the difference between success and failure. Many experienced physi-

2. Barringer, B. S., and Platt, P. S.: A Survey of Venereal Clinics in New York City and a Statistical Efficiency Test, Social Hygiene, i, No. 3, published and reprinted by the American Social Hygietre Association, 105 West liortieth Street, New York City.

3. The records of the two clinics were:

$$
\overbrace{\text { Number Per Cent. }} \text {. }
$$

Fitients dismissed as curred.... 25 Ceased treatment improved..... 50 9.7
19.3
71.0 $\overbrace{\text { Number }}$ Per Cent. $\begin{array}{rr}38 & 9.4 \\ 57 & 14.2\end{array}$ $308 \quad 76.4$ cians believe that the intravenous administration of such remedies as salvarsan, when performed outside the hospital, is attended with serious risk to the patient. Furthermore, such treatment, under the adequate supervision possible in the hospital, is most likely to inhibit the transmissibility of the disease for a considerable period, or even to end its development in early cases. The treatment of many cases of gonococcus infection is surgical, and hospital care is therefore imperative; but there are others frequently denied admission whose prompt recovery and return to normal living and occupation without danger to family or fellow workmen would be greatly increased by those services which can be rendered only under hospital conditions.

There are other reasons why the hospital should be studied as an important factor in the administrative control of venereal diseases. An investigation now being conducted in New York City ${ }^{4}$ has shown that of thirty general hospitals only ten receive patients with recognized cases of syphilis in actively infectious stages; but once admitted on some other diagnosis, twenty-seven give care and treatment, although only seventeen provide the service of a syphilologist. Only nine receive adult patients with gonorrheal infection needing hospital treatment, and two of this number specify that only surgical cases are accepted. Three city hospitals receive and treat active gonorrhea in little girls. Thirteen of the thirty will not receive medical cases with known complications of syphilis or gonorrhea. Yet during the past year, 2,607 syphilis cases were treated, according to the reports of only fifteen of these hospitals. Again it may be inferred that these conditions are probably typical of every part of the United States.

The investigation referred to will show the need of developing standard requirements for discharging venereal patients from hospitals. Five hospitals require before discharge of a syphilitic patient three tests, technically designated as $(a)$ healed lesions, (b) entire disappearance of symptoms, and $(c)$ one negative Wassermann; thirteen require none of these. One requires for the discharge of a gonorrheic patient two tests, (a) negative complement fixation, and (b) negative prostatic massage (for men) or negative cervical smear (for women); fifteen require neither of these. Ten hospitals refer discharged patients to social service departments for some form of follow-up observation. Both patients and public will profit by active health department supervision of conditions for clinic and hospital treatment and discharge of venereal patients.

5. Extension of hospital social service work to patients with syphilis and gonococcus infection.

The value of social service for dispensary and hospital patients has been generally recognized for practically every class of diseases except the venereal. To the pioneer activities of the Boston Dispensary in cooperation with the Massachusetts Social Hygiene Society, the social service work of the genito-urinary and syphilology divisions of the Massachusetts General Hospital, and the notable efforts of a few other institutions, the credit is due for the application of social service to syphilis and gonococcus infections. No unusual methods or expenditures are involved. Experienced workers have found it possible to obtain the social histories desired and to secure the interested

4. A joint investigation by the Bureau of Public Health and Hygiene of the Association for Improving the Condition of the Poor, and the Committee on Public Health of the New York Academy of Medicine. 
and intelligent cooperation of patients in implicitly obeying instructions for their own treatment and in bringing to the dispensary other members of their families for diagnosis and advice. This work is proving that in social service we have a weapon of very gieat importance in the battle against venereal diseases, and in addition a service for helpfully dealing with the personal, moral and social problems inevitably involved. The latter benefit probably outweighs the medical value of social service.

\section{PROPHYLACTIC MEASURES}

1. Compulsory notification of syphilis and gonococcus infection to the health department for proper action in protecting the public, due precautions being taken to safeguard the rights and privacy of the individuals concerned.

The right of society to demand the immediate reporting of each case of a dangerous communicable disease to the health authorities for such action as may be deemed necessary for public protection is established and enforced for many diseases. The notification of venereal diseases is now required by the laws of eleven states and a number of cities, but these laws have thus far not been enforced to any considerable extent. Partly this may be accounted for by the difficulties which operate against all morbidity returns. but largely it is due to three special factors: The public has been in ignorance of the nature and dangers of these diseases; the physician has believed that duty to his patient bound him to silence, and health departments have offered no practical program for dealing effectively with the problems presented by each case reported. None of these difficulties are insurmountable.

California made venereal diseases reportable by case number in November, 1910, for the purpose of developing a basis for correspondence with physicians on specific cases and the problems of public protection involved. New York City later required reports by names and address of all patients in public or charity hospitals and dispensaries, with the purpose of supplementing the work of the medical profession in private cases, by investigation and supervision of those under treatment in institutions which could not follow up their patients. The state of Vermont has enacted a new law ${ }^{5}$ which requires the name, address, age and sex of each patient, and provides payment of the physician for reporting, and penalty for failure to report.

With complete notification by physicians and full cooperation with dispensaries and hospitals, a health department is in position intelligently to direct its work of protecting the public from all recognized cases. Reference is made below to measures proposed for securing information of other cases.

The logic of compulsory notification must be recognized. The desirability of proper data and the name of each patient being filed with the health department for identification and reference in future laboratory examinations and action, regardless of whether the

5. Sections 3 and 4 of "An Act for the Prevention of Venereal Diseases" effective as a state law, June, 1915, read as follows: "A physician who knows or lias reason to believe that a person whom he treats or prescribes for is infected with either gonorthea or syplitis shall immediately report the name, address, age and sex of such person to the secretary of the State Board of Health, for which report he shal receive the sum of twenty.five cents, to be paid by the State Board of Health. A physician who fails to make such report shall be fined not more than two hundred dollars.

more than two hundred dollars. The State. Board of Health shall make and enforce such rules and regulations for the quarantining of cases of gonorthea and syphitis reported to it as may be deened necessary for the protection of the ptibic. Said board shall not disclose the names or addresses of such persons reported or treated to any person other than a prosecuting patient may have changed physicians, is obvious. Evidence is not lacking to prove that patients receive the best assistance and the public receives the best protection when the physician and the health department work together in full knowledge of who the patient is, where he lives, and how he is occupied. It seems absurd to contend that health departments cannot be made just as trustworthy repositories for personal histories as doctors' offices, private laboratories and hospital wards. In time, it is probable that public opinion will demand that the health officer, as the representative of the people, shall be taken into consultation in dealing with venereal disease patients, just as he is nov: taken into the confidence of physicians dealing with tuberculosis, typhoid fever and other communicable diseases, which experience has shown may be treated by the private physician, provided the public interest is safeguarded through certain supervision by the health department. All the general arguments for complete reporting of other communicable diseases apply to the venereal diseases.

2. Instruction of persons exposed in measures for the protection of themselves and their immediate associates.

To the extent made possible by notification, the most important work in prophylaxis is the instruction of the persons exposed. This implies individual instruction in accordance with the facts for each case. This in turn demands competent, tactful, sympathetic advisers, with time available for getting the facts in each case and using them effectively with the individual. It is in this field especially that the advisory clinic and social service workers are needed. It has been demonstrated that the people will accept and even welcome this service, and that administratively and financially it is practicable.

3. Promotion of continence as the greatest factor in personal prophylaxis.

Turning from the problem of those known to be infected, or definitely exposed, to the unknown majority of the population who should be protected by such prophylactic measures as they may apply continuously themselves, or by which they may be protected through official and community action, sexual continence must be acknowledged as the one from which the greatest reduction of venereal diseases would result-provided it could be generally enforced outside of marriage. Evidence is accumulating which shows that the formation of public opinion in favor of continence outside of marriage is steadily gaining ground.

4. Dissemination of general information concerning syphilis and gonorrhea and their methods of transmission.

All the arguments which favor the dissemination of information regarding any disease apply to the dissemination of information regarding venereal diseases, but it does not follow that the same methods should be used. Without endeavoring in this paper to discuss the details of this important factor in prophylaxis, it may be said that, through health departments and many other agencies, the work has been well begun. The American Social Hygiene Association ${ }^{7}$ has established a national clearing house for information, and many state and city social hygiene societies have been organized to do intensive local work. Other organizations, notably the American Medical Association, have published and distributed large amounts of literature.

7. American Social Hygiene Association, 105 West Fortieth Street, New York City. 
5. Utilization of approved medical prophylactic measures under adequate restrictions and supervision.

That society is not opposed to the popularization of methods for preventing the spread of diseases by means of medical applications, or even to the furnishing at public expense and compelling the use of medical prophylactics, is amply demonstrated by numerous instances. The requirement of vaccination against smallpox, the distribution of diphtheria antitoxin, and the preparation and administration of antirabic treatments are concrete illustrations. The opposition to medical prophylactic measures for venereal diseases is based primarily on the public determination to safeguard something it holds far more precious than health, namely, the morals of the community. The approval accorded the use of silver nitrate preparations in preventing gonococcus infection of babies' eyes is direct evidence that objections to the parallel preventive treatment for syphilis and gonorrhea in adults are not based on medical grounds.

Where it is possible, as in the army and navy, for competent officers to instruct men individually in the nature of venereal diseases and the immediate application of medical prophylactics in the event of exposure, some reluction in their prevalence has been obtained; and these meastires combined with rigid requirements for reporting and follow-up preventive treatment at military quarters have very largely reduced them. ${ }^{8}$ Some of the most experienced officers, however, believe treatment as applied by the medical staff at the military dispensary is the essential factor, and favor the use of the prophylactic packet only by those men who are granted more than ten hours' absence and who cannot be trusted to remain continent. This is such a small number that some officers are opposed to any recognition of self-applied medical prophylactic measures.

In civil life, the difficulties of instructing the general public in the uses and limitations of self-applied medical prophylactics are greatly increased. 'The moral arguments against attempting any such instruction are admittedly logical and strong; but discarding for the moment the relations of medicine to morals, there remains the argument that such prophylactic measures can succed in only a percentage of those cases in which adequate instruction has been given and the individual las the intelligence to apply properly the medical preparations immediately or within a few hours after exposure. Obviously these requirements are not likely to be met by the immature boys, the drink-befuddled men, the defective girls, the average prostitutes, who constitute the bulk of the citizens who might be protected by this method. It seems apparent that medical prophylaxis can wisely be made use of only under the advice of physicians who are fully informed of the circumstances in each case, and have opportunity to observe each individual until the danger of infection has passed.

If personal supervision by a physician is an essential for the effective use of medical prophylaxis, it becomes undesirable to advocate publicly such measures for attempted application by individuals without such supervision. The private practitioner, the dispensary officer and the health department staff constitute the

8. Thus far the most comprehensive and successful work in the reduction of venereal diseases has been done by the army and navy officers. The extension of their examination methods to applicants for enlisinent in all of our large cities is developing a fund of accurate and valuable knowledge concerning a large class of the civilian popula. and valuable knowledge concerning a large class of the civilian popula. tion. This paper does not permit of quotations from reports, but great medical authorities in further studies. qualified persons for the employment of medical treatment designed to prevent the development of venereal diseases after exposure. The avoidance of exposure constitutes the best prophylactic measure to be advocated before exposure and, since there are no practical methods by which the layman can recognize persons who are infected, this means the practice of continence prior to marriage and selection of a marriage mate who has neither syphilis nor gonorrhea in a communicable form. The need for ample facilities at public expense for advisory clinics and treatment of ambulatory cases has been previously mentioned. These facilities should be extended to include applicants who apply immediately after exposure, as well as those who apply when infection has reached a welldefined stage. As in the use of a medical prophylactic for the gonococcal infection of babies' eyes, so in the common vencreal infections the emphasis should be placed on popularizing the need for early and competent advice and treatment, rather than on methods of self-medication.

MEASURES CONTRIBUTING TO THE REDUCTION AND ULTIMATE JRADICATYON OF VENEREAL DISEASES

For the purposes of this paper, the measures contributing to the reduction and ultimate eradication of venereal diseases may be passed over with enumeration of the principal ones which every student of the venereal disease problem must recognize to be vitally important:

1. The repression of prostitution through law cuforcenent.

2. The procision of ample facilities for zoholesome play and recreation, and reduction of environmental and social conditions which encourage extramarital sex relations.

3. The elimination of alcoholic drinks.

4. Promotion of sex cducation and general standards of personal conduct ahich are in kecping with high moral principles.

5. The encouragement of early marriage after maturity has been attained, and promotion of economic and social conditions conducive thereto.

\section{OTHER MEASURES}

An increasing number of experiments are being tried along lines not specifically mentioned in the foregoing presentation of the program for action reported by the American Public Fealth Association committee. The so-called health certificate for marriage, or "eugenic law" as it is popularly called, is one of these. The pur. pose of such laws is primarily to protect matrimony from communicable diseases, particularly venereal diseases, but the administrative basis for such a law has not been satisfactorily developed. Both for the sake of the contracting parties and the children who may be born to them, it is important to develop some plan to meet this purpose, and the private physician and the health department cooperating with the clergy can do a great deal in safeguarding marriage without any law. In foreign countries, as Denmark, Norway and Sweden, where laws of this character have been enacted, the basic principle has been that an individual infected with venereal diseases must not marry unless the other contracting party is informed and both have been given verbal warning of the dangers involved.

A second type of law designed to detect and inhibit the spread of venereal infection is being seriously 
tried by the state of Pennsylvania, and New York, Philadelphia and other cities. The purpose is to eliminate, from the occupations connected with the preparation or serving of foods, persons with a venereal disease in communicable form. Thus far it is encouraging that among 40,000 examinations reported in New York, only 3.5 per cent. (including other in fectious diseases beside syphilis and gonorrhea) have been "found in such a state of health as to make their employment unlawful." Applicants for pedler's licenses have been examined for venereal infection and either refused the license or given it conditionally on submission to adequate treatment. One such series of over 1,000 cases $^{9}$ showed only 8.4 per cent. positive for the Wassermann test for syphilis.

As a matter not of law but of public or business policy, many institutions require physical examination of employees, including tests for venereal diseases. The United States Army and Navy are doing notable work in their endeavor to eliminate from admission applicants with venereal infection. The Rochester Health Department through its infectious disease division is effectively cooperating with employers of men. Railroad and other business corporations with sickbenefit and pension systems, life insurance companies, and other organizations similarly protect themselves so far as practicable by examination of candidates for employment. Certain colleges include observation for venereal infections as a part of the required physical examination on entrance, and many hospitals require information on the diagnosis of each patient received, refusing admission to those with venereal diseases.

Many experiments have been made and will continue to be made to develop effective and safe methods for immunizing against syphilis, and especially against gonorrhea, but none of them have reached the stage of scientific recognition which warrants discussion of their administrative application. In venereal infections, as in other infectious diseases, according to the intelligence of the individual and his family, and the adequacy of the medical services provided, the patient may be allowed full liberty in the community or should be kept under close supervision by the health authorities. Obviously, there are certain occupations in which an infected person may engage without endangering others through the necessary relations of business. The night watchman, for example, does not present the same occupational problem as the barber or the waiter. Quarantine or other form of segregation during the entire period of danger to others is impracticable in any but the most dangerous cases. It is probable that, as the program for administratively dealing with venereal diseases progresses, ways for protecting the public from them will be devised without unduly limiting the liberty of any but the few who, through special circumstance, low mentality or exceptional antisocial tendencies, must be properly segregated as dangerous carriers. In dealing with tuberculosis, the people have decided that it is wise to appropriate immense sums for sanatoriums, for treatment, for labor bureaus to place convalescents

9. Social Hygiene, ii, No. 1, p. 140. The other figures quoted here are given for comparison of pedlers with certain other groups of the population:

\begin{tabular}{|c|c|c|c|}
\hline & Exarined & Number & Per Cent \\
\hline (men aw & 446 & 49 & 10.9 \\
\hline ormato & $5+4$ & 37 & 6.8 \\
\hline rd Reforma & 19 & 78 & 40.8 \\
\hline ntiary, Blackwell's Island (mixed) & 253 & 62 & 24.5 \\
\hline well's Ysland (mixed) & 3,0 & 1,468 & 48.2 \\
\hline nse to & 1,117 & & 8.4 \\
\hline
\end{tabular}

in occupations which will safeguard the public and benefit the patient, and for dispensaries to begin and end the public supervision of infected individuals. Venereal diseases constitute an equally serious problem which the public must attack in an equally thorough manner.

Sterilization of infected persons has frequently been advocated to the confusion of the public health program, as it must be evident that artificial sterility, like the involuntary sterility due to gonorrhea, can do nothing in the campaign for prevention, except for the next generation by ensuring that no infected children will be born. The advocates of a number of measures such as this are confusing the venereal disease problem with the application of the principles of heredity.

Another proposal which seems unwise as a public health measure is the penalizing of infected individuals. For disciplinary purposes, as illustrated by the reduction of pay in armies and navies during the period of illness from venereal disease, or financial reasons, as in the barring of this class of patients from medical benefits in fraternal orders, or for other reasons, such measures may in their narrow application seem justified. But this whole group of procedures has little to show as concrete evidence of being effective against disease or even a deterrent of immoral practices.

\section{IN CONCLUSION}

It must be emphasized that the public should clearly understand that medicine and morals have a large $\mathrm{ccm}$ mon ground of interest in the prevention of syphilis and gonococcus infections. Every effort should be made to develop the same attitude toward these diseases that is manifested toward other dangerous communicable infections, that is, one of sympathy and assistance for the individual during illness and recovery, and searching inquiry into the source of the infection and the community conditions which may have contributed to the opportunity for infection. The social ostracism often exhibited without any endeavor to deal constructively with the problem avails nothing either for medicine or morals. It is possible to deal scientifically with venereal diseases and at the same time to advocate that every individual should know that sex relations outside of marriage not only expose him to diseases which may prove disastrous to himself and others but will unfit him for his highest efficiency in citizenship, marriage and parenthood, and that society has a right to expect each man and woman to set for younger people an example of self-respect and self-control in accordance with the standards of moral living which the experience and suffering of past generations have developed.

The Social Background of School Hygiene Work.-What is the value of and the motive force for all the health work, in school and out of it, that is now being undertaken? One can readily see that it has far reaching social, economic and moral phases. Evidently it is an attempt to make sanitation universal, to eliminate preventable disease, to perfect the social and individual health status. It means increased human efficiency, greater earning capacity, a normal social life and a better physical foundation for sound social and spiritual growth. It indicates that society is attempting to meet its social responsibility by protecting the whole of human kind from the menace of its defective members. It recognizes that one of the keenest socio-sanitary indices of a community's life is the care which it takes of its future citizens.-Donald B. Armstrong, M.D., American Journal of Public Health, December, 1915. 